tion. ${ }^{+}$The anomaly, however, seems likely to relate to the genetic origins of Rett syndrome. If as we suspect it is peculiarly associated with the Rett syndrome this will be a helpful, although not pathognomonic sign. More important it may provide a clue to the location of the genetic defect and the timing or nature of the developmental insult to the brain.

A M KERR Royal Hospital for Sick Children and Quarrier's Monitoring Unit, Quarrier's Homes, Bridge of Weir, Renfrewshire PAII 3SA

P ROBERTSON National Hospital, Larbert FK5 4SD

J MITCHELL Department of Statistics, Strathclyde University, Glasgow

1 Rett A. Uber ein eigenartiges hirnatrophisches Syndrome bei hyperammonamie im Kindesalter. Wyndrome bei hyperammonamie im Kindes Wochenschr 1966; 116: 723-6.

2 Kerr A. Rett syndrome: British longitudinal study (1982-1990) and 1990 survey in mental retardation and medical care. In: Roosendaal JJ, ed Proceedings of the European congress on mental retardation and medical care. April 21-24, 1991. Zeist: Uitgeverij Kerckebosch, 1992

3 Ray A, Haldane J. The genetics of a common Indian digital abnormality. Proc Natl Acad Sci USA 1965; 53: 1050-3.

4 Southall D, Kerr A, Tirosh E, Amos P, Lang M, Stephenson J. Hyperventilation in the awake syndrome. Arch Dis Child 1988; 63: 1039-48.

\section{Drug abuse in children and adolescents: an} update

EDITOR, - I read with interest the annotation by $H$ Swadi, which was a most helpful overview of drug abuse in children and adolescents. Although illicit drugs are one of the main sources of substance abuse, iatrogenic sources also form a significant proportion.

Abuse of prescribed pressurised aerosols (antiasthmatic inhalers) by young children and adolescents is little known and possibly underestimated. ' Young asthmatics are at risk of this form of drug abuse and may manifest acute psychotic symptoms. Addiction is probably to the fluorinated hydrocarbons used as propellants, rather than the active substance itself.

The medical profession, primarily general practitioners, must be made aware of this unusual source of drug abuse, especially in any young asthmatics presenting with bizarre behaviour.

V P PRASHER

Department of Psychiatry Uniersity of Birmingham
Birmingham $B 132 Q Z$

1 Swadi H. Drug abuse in children and adolescents: an update. Arch Dis Child 1992; 67: 1245-6.

2 Prasher VP, Corbett JA. Aerosol addiction. $\mathrm{Br} \mathcal{F}$ Psychiatry 1990; 157: 922-4.

\section{What do parents know about vitamins?}

EdroR, - Health professionals should also aim, and be reminded, to improve supervision of vitamin supplementation', say Dr Ko and colleagues.' I would draw a different conclusion: stop recommending routine vitamins, except to high risk groups. Parents are clearly indicating their lack of enthusiasm for this practice, and surely hard pressed health visitors have better things to do when the value of vitamins for all babies is questionable. Fluoride supplements, yes - but health profes- sionals would be better advised to devote their energies to pressing for water fluoridation, than reminding parents to do their duty.

TONY WATERSTON Newcastle Health Authority, Community Headquarters, Community Headquarters,
Newcastle General Hospital, Westgate Road,
Newcastle upon Tyne NE4 6BE

1 Ko MLB, Ramsell N, Wilson JA. What do parents know about vitamins? Arch Dis Child 1992; 67 1080-1.

\section{SPRING BOOKS}

\section{Titillating book reviews}

Why are first editions collected when second editions are rarer and better? If you are still reading this page I have achieved the firs objective of a book reviewer, which is to entice the reader to start reading the piece. We ask our reviewers to provide a sparkling first paragraph but perhaps we should encourage them to use the device of the literary supplements where irrelevant but titillating trash is used to ensnare the reader. Recent revelations that reviews in these august periodicals are often compiled by close associates of the authors is in contrast with our policy of choosing a reviewer who is not known personally to the author. The book review section is the only part of the journal that is not peer reviewed and it is difficult to see how we could achieve that objective. We try to select a reviewer of appropriate experience but subjectivity is inevitably introduced, for example, an undergraduate textbook may be reviewed by a clinical tutor or an undergraduate.

We tend to avoid reviewing conference proceedings as the material is often published several years after presentation and long after the definitive peer reviewed paper has been published. The late Clifford Hawkins wrote reviews of new editions comparing them with the previous editions as a regular feature in the $B M$. This journal could carry a similar section if there was a demand. Paediatric orthopaedic surgeons seem to produce a new book every few months and there must be a limit to the number of reviews of new books on this subject that will attract our readers. Book reviews should be entertaining as well as informative. Have you any tips that may help the editors to achieve this goal?

\section{BERNARD VALMAN}

Editor

Fetal and Infant Origins of Adult Disease. Edited by D J P Barker. (Pp 343; £24.95 hardback.) BMJ, 1992. ISBN 0-7279-0743-3.

There can be few British paediatrician unaware of the work currently proceeding in Southampton University regarding the early origins of adult disease, but probably not many have been able to study the full reports, or to have formed a view of the importance of the work. All this is provided in this volume, which includes 31 relevant articles from a large number of different journals, and is prefaced by a very readable and balanced critique by Roger Robinson.

The work by David Barker and his group was initiated by the observation that geographical areas that had had high infant mortality rates in the earlier parts of the century were now those with high rates of adult ischaemic heart disease. This prompted a search for obstetric and infant health records dating from that time, and the follow up and examination of the health of the individuals for whom these data were available, as well as the use of data from two of the national longitudinal studies. The description of the ingenious methodology used itself warrants the purchase of the book. But the subsequent studies that relate placental weight and fetal and infant growth rate to adult blood pressure, risk of ischaemic heart disease and stroke, and to the risk of non-insulin dependent diabetes read like a series of detective stories, and can be recommended for holiday reading.

The results have lead to a series of very plausible and sometimes complex hypotheses that raise basic and very important questions regarding influences on intrauterine growth and coping mechanisms when uterine nutritional supplies are constrained. The work also introduces the readers to the fundamental differences between birth cohort effects and effects stemming from the health behaviour prevalent during the period under study. Thus many of the conclusions have been questioned by those who see adult health behaviour such as smoking, diet, and exercise as having more influence than early experience. Almost certainly both are highly relevant, and what needs to be assessed is their relative importance.

Whatever the final outcome of the lively discussions that this work has initiated, David Barker and his team have performed a great service by carrying out and stimulating research in a field of fundamental importance, and by linking the interests of paediatricians and adult physicians. The book is entertaining, intellectually challenging, of a modest price, and highly recommended.

EVA ALBERMAN
Emeritus professor of clinical epidemiology

Forfar and Arneil's Textbook of Paediatrics. 4th Ed. Edited by A G M. Campbell and Neil McIntosh. (Pp 2067; £125 hardback.) Churchill Livingstone, 1992. ISBN 0-44304193-8.

I have heard senior paediatricians say that they never refer to textbooks but read only monographs and journals. I have never been one of their company. Perhaps they have perfect memories, know everything, and never need to stop to check a point. I envy them; I have an imperfect memory, know far less than everything, and need fairly frequent pit stops to check that my tyres aren't flat. (I also have a fairly voracious appetite for journals and the odd monograph.) In recent years when I have needed to check on a general point in paediatrics I have gone to Forfar and Arneil or the latest edition of Nelson's textbook or, very often, both and have found little to choose between them. Last year saw the appearance of this fourth edition of Forfar and Arneil and the fourteenth edition of Nelson. Both have been extensively revised, rewritten, and updated. They are of almost identical size and scope and their factual content is very similar. (It is not true, of course, that all American writers have the literary skills of Donald Duck whereas all 